\title{
Commentary
}

\section{Mental Fatigue: A Public Health Concern?}

\author{
Jessica W. Chow, PhD* \\ Department of Exercise Science, St. Thomas Aquinas College, School of Arts and Sciences, Sparkill, NY 10976, USA

\section{"Corresponding author} \\ Jessica W. Chow, PhD \\ Assistant Professor of Exercise Science, St. Thomas Aquinas College, School of Arts and Sciences, Sparkill, NY 10976, USA; E-mail: jchow@stac.edu
}

\section{Article information}

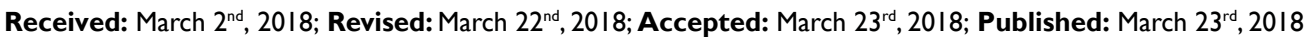

\section{Cite this article}

Chow JW. Mental fatigue: A public health concern? Sport Exerc Med Open J. 2018; 4(I): I-2. doi: 10.17I40/SEMOJ-4-I53

I

n our current societal state of rapid technological advancement, we are constantly being exposed to various mediums of information. Obtaining information is just a matter of a few taps away on one's phone. The ease in accessing information has its benefits and shortfalls. While the ease in acquiring information is an obvious advantage, the downside though, is the fatigue associated with the constant processing of information on a daily basis. Adding on the multitude of responsibilities that everyone has while including the balancing of personal and professional obligations, the symptoms of mental fatigue is perhaps more prevalent than those associated with physical fatigue where symptoms are visible to identify and perceive.

Mental fatigue is characterized with subjective feelings of "tiredness" and "lack of energy". This psychobiological state has been extensively researched on professions where cognitive demand is very high, such as drivers and air pilots ${ }^{1,2}$ and its contribution to the development of work-related musculoskeletal disorders. ${ }^{3}$ It has been reported that in the United States, approximately $29 \%$ of adults reported sleeping less than 7 hours per night ${ }^{4}$ and an estimated 70 million suffer from a sleep disorder or chronic sleep deprivation $^{5}$ with similar subjective consequential symptoms. ${ }^{6}$ In a study by The Pulse Institute (2014), where employees from three U.S. based companies were surveyed, $76 \%$ of employees felt tired most days of the week, $40 \%$ doze off during the day once per month, 30\% were unhappy or very unhappy with the quality or quantity of their sleep, and $15 \%$ reported to doze off during the day at least once per week to once per day. ${ }^{7}$

The impact of mental fatigue on workplace productivity is just one spectrum of recent research. The effects on subsequent physical performance in humans has been researched in various populations as well, such as professional road cyclists, soccer players, and intermittent team sport athletes. ${ }^{8-10}$ Dating back to as early as 1891, Angelo Mosso published observations of reduced muscular endurance in two physiology professors following long lec- tures and examinations. ${ }^{11}$ Presently, there is surmounting body of evidence reflecting changes in neural function related to reaction time, concentration, endurance performance, and in patients with chronic fatigue syndrome. ${ }^{12-17}$

It has been reported that people who are mentally fatigued reported greater difficulty maintaining concentration and a reduced ability to complete tasks and vigorous exercise due to loss of motivation and tolerance to physical fatigue related symptoms. ${ }^{18-20}$ It is well documented that driving and sleep deprivation, alternatively known as drowsy driving, has a crucial role to traffic accidents. ${ }^{21}$ Similar deprivations in exercise physiological responses have also been observed. ${ }^{22}$

This raises the need for further research to elucidate the role of mental fatigue induced by excessive information processing enabled by the advancement of technology and its role on society's overall well being. Populations of interest may include, but not limited to the clinical population of various chronic diseases, children, adolescence, athletes of various skill levels and sports, and occupations that are subjected to prolonged cognitive activity.

\section{REFERENCES}

1. Goode JH. Are pilots at risk of accidents due to fatigue? I Safety Res. 2003; 34: 309-313. doi: 10.1016/S0022-4375(03)00033-1

2. Lal SK, Craig A. A critical review of the psychophysiology of driver fatigue. Biol Psychol. 2001; 55: 173-194. doi: 10.1016/S03010511(00)00085-5

3. Mehta R, Agnew M. Influence of mental workload on muscle endurance, fatigue, and recovery during intermittent static work. Eur J Appl Physiol. 2012; 112(8): 2891-2902. doi: 10.1007/s00421011-2264-x 
4. Schoenborn CA, Adams PF. Sleep duration as a correlate of smoking, alcohol use, leisure-time physical inactivity, and obesity among adults: United States, 2004--2006. 2009. Web site. http:// www.cdc.gov/nchs/data/hestat/sleep04-06/sleep04-06.pdf. Accessed March 20, 2018.

5. National Heart, Lung, and Blood Institute. Your guide to healthy sleep. National Institutes of Health. NIH Pub No. 06-5271. Department of Health and Human Services. 2005.

6. Shen J, Barbera J, Shapiro CM. Distinguishing sleepiness and fatigue: Focus on definition and measurement. Sleep Med Rev. 2006; 10(1): 63-76. doi: 10.1016/j.smrv.2005.05.004

7. Turgiss J, Allen S. Asleep on the job. The causes and consequences of employees' disrupted sleep and how employers can help. The Pulse Institute. 2014. Web site. http://connect.virginpulse.com/asleep-on-the-job-report-from-virgin-pulse.pdf. Accessed March 20, 2018.

8. Martin K, Staiano W, Menaspà P, et al. Superior inhibitory control and resistance to mental fatigue in professional road cyclists. PLoS One. 2016; 11(7): e0159907. doi: 10.1371/journal.pone.0159907

9. Smith MR, Coutts AJ, Merlini M, Deprez D, Lenoir M, Marcora SM. Mental fatigue impairs soccer-specific physical and technical performance. Med Sci Sports Exerc. 2016; 48(2): 267-276. doi: 10.1249/MSS.0000000000000762

10. Smith MR, Marcora SM, Coutts AJ. Mental fatigue impairs intermittent running performance. Med Sci Sports Exerc. 2015; 47(8): 1682-1690. doi: 10.1249/MSS.0000000000000592

11. Mosso A. La fatica [n Italian]. Milan, Italy: Treves; 1891.

12. Cook DB, O'Connor PJ, Lange G, Steffener J. Functional neuroimaging correlates of mental fatigue induced by cognition among chronic fatigue syndrome patients and controls. Neuroimage. 2007; 36: 108-122. doi: 10.1016/j.neuroimage.2007.02.033

13. Faber LG, Maurits NM, Lorist MM. Mental fatigue affects visual selective attention. PLoS One. 2012; 7(10): e48073. doi: 10.1371/ journal.pone.0048073
14. Hopstaken JF, van der Linden D, Bakker AB, Kompier MAJ. A multifaceted investigation of the link between mental fatigue and task disengagement. Psychophysiology. 2015; 52: 305-315. doi: $10.1111 /$ psyp.12339

15. Lim J, Kwok K. The effects of varying break length on attention and time on task. Hum Factors. 2016; 58(3): 472-481. doi: $10.1177 / 0018720815617395$

16. Mehta RK, Parasuraman R. Effects of mental fatigue on the development of physical fatigue: A neuroergonomic approach. Hum Factors. 2013; 56(4): 645-656 doi: 10.1177/0018720813507279

17. Van Cutsem J, Marcora S, De Pauw K, Bailey S, Meeusen R, Roelands B. The effects of mental fatigue on physical performance: A systematic review. Sports Med. 2017; 47(8): 1569-1588. doi: 10.1007/s40279-016-0672-0

18. Meijman TF. Mental fatigue and the efficiency of information processing in relation to work times. Int J Ind Ergon. 1997; 20: 31 38. doi: 10.1016/S0169-8141(96)00029-7

19. Van der Linden D, Frese M, Meijman TF. Mental fatigue and the control of cognitive processes: Effects on perseveration and planning. Acta Psychol (Amst). 2003; 113: 45-65. doi: 10.1016/ S0001-6918(02)00150-6

20. Van der Linden D. The urge to stop: The cognitive and biological nature of acute mental fatigue. In: Ackerman PL, ed. Cognitive fatigue: Multidisciplinary Perspectives on Current Research and Future Applications. Washington, USA: American Psychological Association; 2011: 149-164.

21. Connor J, Norton R, Ameratunga S, et al. Driver sleepiness and risk of serious injury to car occupants: Population based case control study. BMJ. 2002; 324: 1125. doi: 10.1136/bmj.324.7346.1125

22. Fullagar H, Skorski S, Duffield R, Hammes D, Coutts A, Meyer T. Sleep and athletic performance: The effects of sleep loss on exercise performance, and physiological and cognitive responses to exercise. Sports Med. 2015; 45(2): 161-186. doi: 10.1007/s40279014-0260-0 